\section{Horta de plantas medicinais para uso terapêutico e nutricional}

Dulci N. F. Vagenas

Daniela Fagioli

Professoras da Universidade Paulista.

\author{
Altamiro Rodrigues \\ Funcionário da Associação \\ Beneficente Comunidade de Amor \\ Rainha da Paz.
}

Marta Leni O. S. De Campos

Aluna do curso de Farmácia.

Universidade Paulista.
Universidad y salud /

Intervenciones
Resumo

A Organização Mundial da Saúde estima que quase $85 \%$ da medicina tradicional envolve o uso de plantas medicinais, seus extratos vegetais e seus princípios ativos. O objetivo desse trabalho foi criar uma horta de plantas medicinais nas instalações de uma Associação Beneficente, Santana de Parnaíba, São Paulo e ensinar às mães como plantar, colher, preparar e ministrar os chás. Foi realizado o plantio de 11 plantas medicinais de consonância com a regulamentação da Agência Nacional de Vigilância Sanitária, para uso terapêutico e nutricional. Até o presente momento foi realizado o primeiro mutirão da saúde, onde foi oferecido chá de hortelã e um folder explicativo como modo de preparo e no mês de maio/2014, a semana de saúde e beleza, onde oferecemos chá de manjericão e pesto. Ressalto que os participantes apresentaram elevada aceitabilidade, avaliando como excelente, pois os mesmos são de fácil preparo e sabor muito agradável.

Palavras-chave

- plantas medicinais

- terapêutico

- nutricional

- hortelã-chá

\section{Introdução}

O Padre José de Anchieta (1560-1580) foi o primeiro a descrever o uso das plantas medicinais do Brasil. Até hoje as plantas medicinais são usadas com fins de tratamento, cura de doenças e para prevenção e bom funcionamento de todos os sistemas fisiológicos humanos.

A Organização Mundial da Saúde estima que 80 \% da população mundial utiliza a medicina tradicional para suas necessidades básicas de saúde e que, quase $85 \%$ da medicina tradicional envolve o uso de plantas medicinais, seus extratos vegetais e seus princípios ativos (Akerele, 1993).

As plantas medicinais desempenham importante papel na nutrição humana em todas as faixas etárias, como fonte de vitaminas, sais minerais e fibras. Além disso, também destaca-se a preocupação com o uso eficiente dos recursos naturais não renováveis, manutenção da biodiversidade, preservação ambiental, desenvolvimento econômico e qualidade de vida humana em um ambiente sustentável (Brito e Freitas, 2004).

Neste contexto, a horta orgânica de plantas medicinais refere-se a uma produção baseada em tecnologias limpas e sustentáveis, sem agrotóxicos, que pode ser aliada à preocupação das pessoas com o seu bem-estar, através da alimentação com produtos naturais, como frutas, legumes e hortaliças, sejam elas folhosas, raízes ou caules (Winter e Davis, 2006).

Utiliza-se a compostagem, que é produzida a partir das folhas de árvores, restos de cozinha, mato capinado, cinzas, cascas de frutas e outros. Apresenta facilidade em seu preparo em casa, uma vez que basta misturar na terra todos esses ingredientes, os quais são ricos em aminoácidos e ácidos húmicos, que atendem as exigências nutricionais da planta. São biorreguladores gerando resistência orgânica a pragas, doenças e ao stress hídrico (Hayes et al., 2001; Teixeira et al., 2002).

Contudo, contempla também atividade socioambiental, desenvolve a capacidade de trabalho cooperativo em equipe, ampliando a consciência da importância de ações solidárias individuais e coletivas (Filgueira, 2003; Brito e Freitas, 2004), ressaltando-se a inclusão social de pessoas carentes, pois permite o tratamento de problemas de saúde através da utilização das plantas medicinais (Paixão et al., 2013).

Em termos educacionais, constrói o senso de responsabilidade, de valores mais humanizados e permeia todo o processo de aprendizado, estabelecendo relações saudáveis entre meio ambiente e sociedade.

O objetivo deste projeto foi ensinar o plantio da horta de plantas medicinais e sua utilização terapêutica e nutricional com as mães, crianças e adolescentes com deficiências múltiplas atendidas na Associação Beneficente Comunidade Amor Rainha da Paz, localizada na Estrada do Surú, Santana de Parnaíba, São Paulo, Brasil. Esta associação, criada em 2001, beneficia aproximadamente 300 crianças e adolescentes carentes, portadores de necessidades especiais e deficiências múltiplas e suas famílias, é uma entidade sem fins lucrativos, cedeu suas instalações para a montagem da horta de plantas medicinais.

Atua em diversas áreas e promove a assistência social, possui um consultório odontológico, uma sala de fisioterapia, uma de terapia ocupacional, de Informática, de fonoaudiologia, uma cozinha industrial, uma padaria, uma enfermaria, o setor de neurologia e a brinquedoteca. 


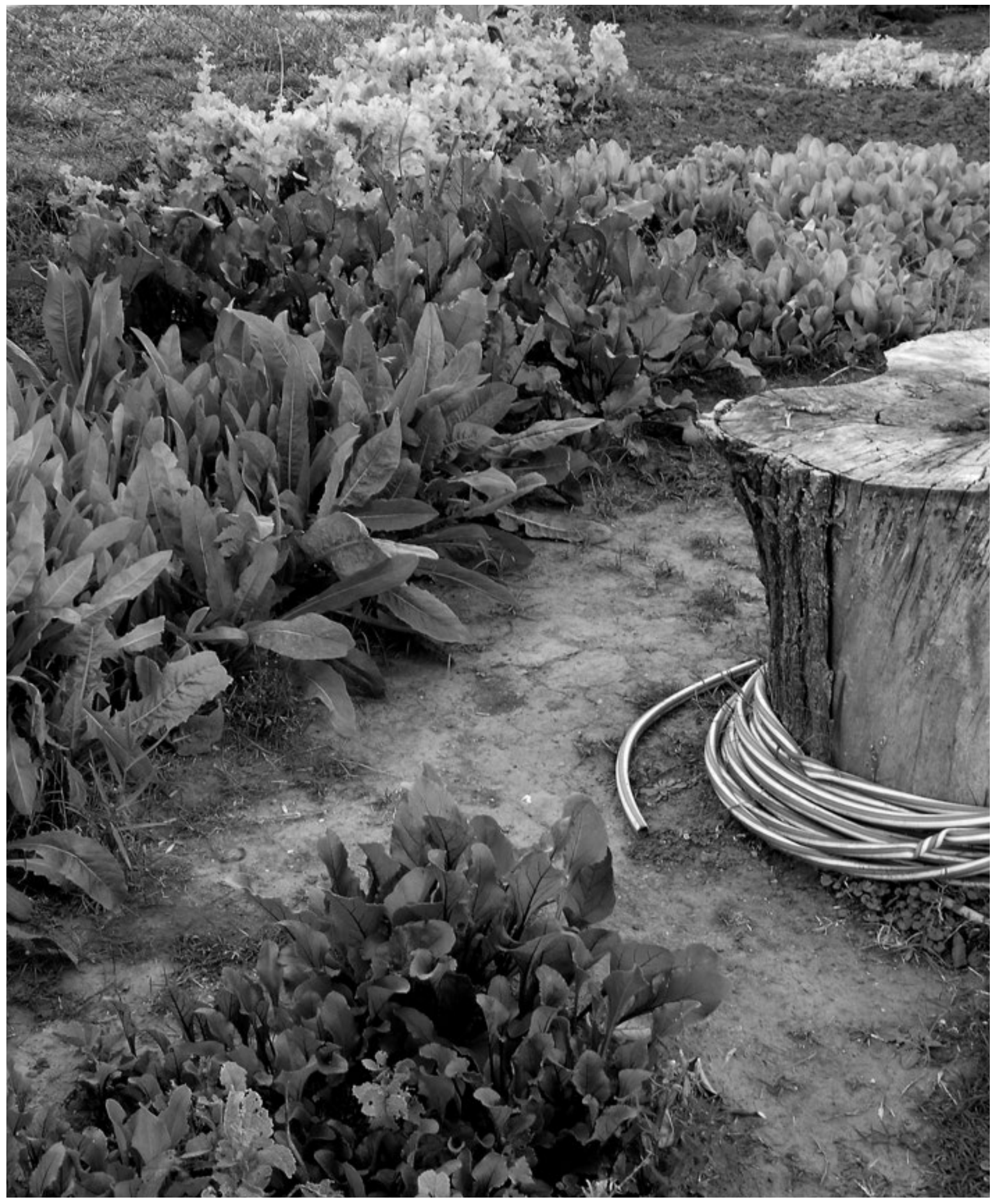


Atualmente, mantém quatro subprojetos: Cuidar de quem cuida da gente; João de Barro; Mãos dadas e vivaleite, que possuem como principal objetivo o resgate da autoestima; melhoria das condições habitacionais e do vínculo familiar.

A Universidade Paulista, campus Alphaville, forneceu docente responsável e os alunos de graduação do curso de farmácia e nutrição.

\section{Desenvolvimento}

- Primeira parte do projeto: escolha da área para o plantio e o início do processo de compostagem.

Para a implantação de uma horta orgânica com plantas medicinais foi escolhido um local de fácil acesso, terreno plano com boa insolação, fartura de água e bom solo. Cada planta medicinal apresenta características próprias, ciclo de vida, época para o plantio, necessidade de nutrientes e água (Lucon e Chaves, 2004).

- Segunda parte do projeto: escolha das plantas medicinais. As plantas medicinais que foram utilizadas nesta atividade estão em consonância com a regulamentação da Agência Nacional de Vigilância Sanitária (ANVISA, RDC N¹0/2010), assim são aprovados para uso terapêutico: Rosmarinusofficinatis (alecrim), Cymbopogoncitratuns (capim cidreira), Matricaricrecututa (camomila), Pimpinela anisun (erva-doce/ anis), Baccharistrimera (carqueja), Ocimumbasilicum (manjericão), Mikaniaglomerata (guaco), Mentha (hortelã), Phyllanthusniruni (quebra-pedra), Menthapulegium (poejo), Salviaofficinalis (salvia).

A escolha das plantas ocorreu após questionamento às mães sobre os principais problemas de saúde das crianças. Desta forma, os problemas digestivos foram os mais representativos (80\%) entre os cadeirantes, pois apresentam constantemente queixas de gases, má digestão, obstipação, entre outros; as queixas respiratórias, como gripes, pneumonia, rinite, sinusite, bronquite e asma, também apresentaram destaque, além das queixas urinárias que incluíam as infecções urinárias e cálculos renais.

- Terceira parte do projeto: produção da compostagem. A compostagem foi elaborada com resíduos orgânicos provenientes da cozinha da instituição (restos de frutas, casca de cebola, batata, cenoura, guardanapo, arroz, feijão etc.), folhas de restos de capina do jardim, borra de café e chá da cozinha. Os resíduos foram colocados na terra com burracos de $1 \mathrm{~m}$ de altura e 0,70 m de diâmetro, em camadas alternadas (terra/resíduos) e irrigadas. A irrigação e o reviramento das pilhas foram realizadas a cada sete dias.

- Quarta parte do projeto: passo a passo para o plantio.

- Passo 1: preparo do canteiro de $1 \mathrm{~m} \times 2 \mathrm{~m}$ com terra da compostagem em um local com adequada drenagem natural;

- Passo 2: distribuição as mudas de plantas medicinais no centro do canteiro, deixando uma distância de aproximadamente $15 \mathrm{~cm}$ entre uma e outra;

- Passo 3: cobertura com um pouco de terra toda a raiz da planta;
- Passo 4: irrigação das mudas com um pouco de água, pelo menos uma vez ao dia. Em dias muito quentes, duas vezes ao dia (pela manhã e à noite) até as mudas emergirem.

- Quinta parte do projeto: educacional.

As mães que possuem filho(s) com deficiências múltiplas foram orientadas, durante a oficina culinária, a prepararem os chás específicos que devem ser ministrados de acordo com a sua necessidade.

\section{Resultados e discussão}

O plantio das mudas das plantas medicinais iniciou-se em setembro de 2013 com a seleção de 11 espécies diferentes (Tabela 1), selecionadas de acordo com as necessidades das crianças após uma triagem com as mães para o levantamento dos principais problemas de saúde das crianças e adolescentes. A primeira coleta aconteceu em outubro do mesmo ano, quando realizamos o primeiro mutirão da saúde na Instituição Rainha da Paz. Neste evento escolhemos preparar o chá de hortelã, pois $80 \%$ das crianças e adolescentes são cadeirantes e $60 \%$ apresentam problemas de má digestão.

O preparo do chá foi realizado na cozinha da instituição Rainha da Paz: utilizamos folhas frescas coletadas pela manhã (10 g para 1 litro de água fervente), preparamos a infusão acrescentando as folhas e tampando até resfriar. Logo em seguida, coamos e servimos a os participantes do primeiro mutirão da saúde (UNIP/Rainha da Paz) juntamente com a distribuição de folder explicativo sobre a propriedade da hortelã, indicações, uso digestivo e contra indicação. Observamos que o chá de hortelã teve boa aceitação por parte das crianças, adolescentes e adultos que participaram do mutirão, pois ele tem aroma suave e sabor muito agradável ao paladar.

Nos dias 5 ao 9 de maio de 2014 realizamos a semana da saúde e beleza para as mães, onde ensinamos a preparar chá de manjericão (dez folhas frescas para meio litro de água fervente) e molho/pesto (um maço das folhas frescas e lavadas, $100 \mathrm{~g}$, uma xícara de chá de azeite, um dente de alho, sal a gosto, triturados no liquidificador).

\section{Conclusão}

Com o presente estudo foi possível concluir que a produção de uma horta orgânica de plantas medicinais, como atividade terapêutica e a utilização dos seus produtos possibilitou ampliar os conhecimentos referentes ao plantio, propriedades e a utilização das plantas para usos medicinais e nutricionais, além de melhorar o bem-estar das crianças e adolescentes com deficiências múltiplas, e ampliou o vínculo entre mãe e filho.

Também foi possível comprovar que, quando existem parcerias entre Universidade e Comunidade, torna-se viável a troca de informações científicas e conhecimentos populares, resultando em benefício recíproco. 
Tabela 1

\begin{tabular}{|c|c|c|c|}
\hline Nome Popular & Nome Científico & Indicações & Contra indicações \\
\hline Alecrim & Rosmarinus officinalis & Antiespasmódica, analgésica, antiinflamatória. & Gestantes: pode provocar aborto. \\
\hline Capim-cidreira & Cymbopogoncitratus & Ansiolítico, antidiarréico, vasodilatador. & Dose alta pode causar desmaios. \\
\hline Camomila & Chamomilla recutita & $\begin{array}{l}\text { Antiespasmódico, anti-hemorroidária, } \\
\text { antidispéptica. }\end{array}$ & Pode causar rinite alérgica. \\
\hline Hortelã & Mentha & Digestivo, vermífugo, expectorante. & Uso prolongado pode causar insônia. \\
\hline Quebra-pedra & Phyllanthus niruri & Diurética, antinefrítica, anticancerígena. & Pode ser tóxica em doseselevadas. \\
\hline Guaco & Mikania glomerata & $\begin{array}{l}\text { Expectorante, antiasmático, antitussígeno, } \\
\text { antiiflamatório. }\end{array}$ & Uso prolongado pode provocar hemorragias. \\
\hline Poejo & Mentha pulegium & Digestivo, vermífugo, expectorante. & Gestantes: pode provocar aborto. \\
\hline Erva-doce & Pimpinella anisum & Calmante, mucolítico, diurético. & $\begin{array}{l}\text { Não devem ser usados em pacientes com } \\
\text { problemas crônicos gastrointestinais. }\end{array}$ \\
\hline Carqueja & Baccharis trimera & Hepatoprotetora, digestiva, antigripal. & Gestantes: pode provocar malformações fetais. \\
\hline Manjericão & Ocimumbasilicum & Digestivo, desintoxicante, diurético. & Gestantes e Lactantes não devem fazer o uso. \\
\hline Sálvia & Salvia officinalis & Cicatrizante, antisséptica bucal, antinflamatória. & $\begin{array}{l}\text { Não deve ser usada por gestantes, } \\
\text { estimula contrações uterinas. }\end{array}$ \\
\hline
\end{tabular}

Fonte: elaboração própria, baseado: Ministério da Saúde, 2006; Costa, 2002; Paixão et al., 2013.

\section{Referências}

Agência Nacional de Vigilância Sanitária, ANVISA (2013). Plantas medicinais. http://portal.anvisa.gov.br/ (último acesso em 12/12/2013).

Akerele, O. (1993). "Summary of who guidelines for the assessment of herbal medicines". Herbal Gram, 28, pp. 13-20.

Albuquerque, U. P. e Hanazaki N. (2006). "As pesquisas etnodirigidas na descoberta de novos fármacos de interesse médico e farmacêutico: fragilidades e perspectivas". In Rev. Bras. Farmacogn, 16 (Supl.), pp. 678-689.

Barbosa, F. G. (2003). Contribuição ao conhecimento químico de três quimiotipos de Lippiaalba (Mill.) N. E. Brown, cultivados no horto de plantas medicinais da UFC. Tese de Doutorado em Química Orgânica, Universidade Federal do Ceará, Brasil. Política Nacional de plantas medicinal e fitoterápico. Brasília.

Brito, W. A. e Freitas, M. A. A. (2004). "Horta orgânica: segurança alimentar do campo à mesa". Aracaju: EMDAGRO, 22p. il. (EMDAGRO. Série Tecnologia Agropecuária, 06). Costa, A. E. (2002). "Nutrição e Fitoterapia". Porto Alegre, RS: Vozes Ltda. - Universidade Federal de Santa Maria.

Filgueira, F. A. R. (2003). Novo manual de olericultura. 2a . edição. Viçosa: Universidade Federal de Viçosa.

Hayes, M. H. B. e Clapp, C. E. (2001). SoilSci. pp. 723. [Link].

Julião, L. S.; Tavares, E. S.; Lage, C. L. S.; Leitão, S. G. (2003). "Cromatografia em camada fina de extratos de três quimiotipos de Lippiaalba (Mill.) N. E. Br. (erva cidreira)". Rev. Bras. Farmacogn, 13, pp. 36-38.
Lucon, C. M. M. e Chaves, A. L. R. (jan./dez. 2004). Palestra-Horta Orgânica. Biológico, São Paulo, 66, n.1/2, pp. 59-62.

Micheref, S. M. e Barros R. (2001). Proteção de plantas na agricultura sustentável. Recife: Imprensa Universitária da UFRPE.

Ministério da Saúde, Secretaria de Ciência, Tecnologia e Insumos Estratégicos, Departamento de Assistência Farmacêutica (2006).

Osterroht, M. (2001). O sítio ecológico e produtivo: horta, pomar e solo fértil. Botucatu: Ed. Agroecológica.

Paixão, J. L. F.; Humberto, D. e Oliveira, J. E. Z. E. (ago. 2013). "Horta orgânica de ervas medicinais: inclusão social na comunidade da Barra em Muriaé/MG Brasil”." Revista Agrogeoambiental, 5, № 2, caderno II, pp. 19-30. Pouso Alegre. Ribeiro, S. M. L.; Silva, R. C.; Castro, I. A. e Tirapegui, J. (2005). "Nutritional assessment of handicapped individuals involved on physical activity".

Nutr Research, 25, pp. 239-249.

Ricci, M. S. F. e Neves, M. C. P. (2006). "Cultivo orgânico de café. Sistemas de Produção". 2:http://www.cnpab.embrapa.br/publicacoes/sistemasdeproducao/ cafe/index.htm (último acesso em 12/12/2013).

Teixeira, L. B.; Germano, V. L. C.; Oliveira, R. F. e Furlan Júnior, J. (2002). Processo de Compostagem a Partir de Lixo Orgânico Urbano e Caroço de Açaí. Belém, PA: Embrapa Amazônia Oriental.

Winter, C. K. e Davis, S. F. (2006). "Organic foods". Journal of Food Science, 71. 